\title{
Making implicit measures of associations with snack foods more negative through evaluative conditioning
}

Citation for published version (APA):

Lebens, H., Roefs, A., Martijn, C., Houben, K., Nederkoorn, C., \& Jansen, A. (2011). Making implicit measures of associations with snack foods more negative through evaluative conditioning. Eating Behaviors, 12(4), 249-253. https://doi.org/10.1016/j.eatbeh.2011.07.001

Document status and date:

Published: 01/01/2011

DOI:

10.1016/j.eatbeh.2011.07.001

Document Version:

Publisher's PDF, also known as Version of record

Document license:

Taverne

Please check the document version of this publication:

- A submitted manuscript is the version of the article upon submission and before peer-review. There can be important differences between the submitted version and the official published version of record.

People interested in the research are advised to contact the author for the final version of the publication, or visit the DOI to the publisher's website.

- The final author version and the galley proof are versions of the publication after peer review.

- The final published version features the final layout of the paper including the volume, issue and page numbers.

Link to publication

\footnotetext{
General rights rights.

- You may freely distribute the URL identifying the publication in the public portal. please follow below link for the End User Agreement:

www.umlib.nl/taverne-license

Take down policy

If you believe that this document breaches copyright please contact us at:

repository@maastrichtuniversity.nl

providing details and we will investigate your claim.
}

Copyright and moral rights for the publications made accessible in the public portal are retained by the authors and/or other copyright owners and it is a condition of accessing publications that users recognise and abide by the legal requirements associated with these

- Users may download and print one copy of any publication from the public portal for the purpose of private study or research.

- You may not further distribute the material or use it for any profit-making activity or commercial gain

If the publication is distributed under the terms of Article $25 \mathrm{fa}$ of the Dutch Copyright Act, indicated by the "Taverne" license above, 


\title{
Making implicit measures of associations with snack foods more negative through evaluative conditioning
}

\author{
Herbert Lebens, Anne Roefs *, Carolien Martijn, Katrijn Houben, Chantal Nederkoorn, Anita Jansen \\ Maastricht University, The Netherlands
}

\section{A R T I C L E I N F O}

\section{Article history:}

Received 15 February 2011

Received in revised form 10 June 2011

Accepted 12 July 2011

Available online 4 August 2011

\section{Keywords:}

Evaluative conditioning

Implicit measures of association

Food consumer behaviour

\begin{abstract}
A B S T R A C T
The present study examined whether implicit measures of associations with snack foods and food consumer behaviour could be changed through a picture-picture evaluative conditioning procedure. In the experimental condition $(n=41)$, female participants completed a conditioning procedure in which pictures of snack foods were paired with images of negatively valenced female body shapes, and pictures of fruits were paired with images of positively valenced body shapes. In a control condition $(n=44)$, snack and fruit stimuli were randomly paired with positively and negatively valenced body shapes. Implicit measures of associations with high-fat snack foods were obtained by using a positive and a negative unipolar single category Implicit Association Test (sc-IAT). A virtual supermarket task was used to assess food consumer behaviour. Results indicated that participants in the experimental condition held a less positive association with high-fat foods on the positive sc-IAT and a more negative association with these foods on the negative sc-IAT as compared to control participants. Opposed to our hypothesis, no behavioural differences were found between the groups. These results imply that this form of associative learning can produce shifts in implicit measures of food evaluations, though behavioural effects were absent.
\end{abstract}

(c) 2011 Elsevier Ltd. All rights reserved.
Despite numerous efforts to emphasise the benefits of healthy eating over the last decades, the average body mass index (BMI) has increased substantially in Western societies (Wang \& Beydoun, 2007). Given that likes and dislikes govern approach and avoidance behaviour (Martin \& Levey, 1978), negative attitudes towards highfat foods are likely to diminish the intake of high-fat foods and, vice versa, positive attitudes towards high-fat foods are likely to increase fat intake. These attitudes are increasingly indexed by so-called implicit measures in both psychopathology and social psychology research (Roefs et al., 2011). De Houwer, Teige-Mocigemba, Spruyt, and Moors (2009) define an implicit measure as "a measurement outcome that is causally produced by the to-be-measured attribute in the absence of certain goals, awareness, substantial cognitive resources, or substantial time" (p. 350). To the extent that implicit measures reflect uncontrollable, unaware, fast mechanisms, they could provide information that augments that from explicit measures. Prior research has shown that implicit measures of attitudes can predict consumer choices (Maison, Greenwald, \& Bruin, 2004; Richetin, Perugini, Prestwich, \& O'Gorman, 2007).

Although some of our likes and dislikes may be innate (Poulton \& Menzies, 2002), it appears that most of our preferences are learned (Rozin \& Millman, 1987). One way in which preferences can be

\footnotetext{
* Corresponding author at: Clinical Psychological Science (UNS40), Maastricht University, P.O. Box 6160, 06200 MD Maastricht, The Netherlands. Tel.: + 31043 3882191.

E-mail address: A.Roefs@maastrichtuniversity.nl (A. Roefs).
}

learned is by evaluative conditioning (EC; Baeyens, Eelen, \& Crombez, 1995; Rozin, Wrzesniewski, \& Byrnes, 1998). EC refers to a change in liking of a stimulus caused by frequent pairings with a second stimulus that either holds a positive or negative valence (De Houwer, Baeyens, \& Eelen, 1994). In this procedure, the initial stimulus is termed the conditioned stimulus (CS), whilst the second stimulus is labelled the unconditioned stimulus (US). Usually, the CS has a neutral valence at first and becomes more positive after being paired with a positive US or more negative after being paired with a negative US.

Prior research has shown that EC can change affective evaluations of foods (Lascelles, Field, \& Davey, 2003) as indexed by explicit measures obtained with a questionnaire. More specifically, it was found that, compared to a preconditioning assessment, affective evaluations of foods became more negative after an EC procedure in which these foods were paired with pictures of obese women. Similar attitudinal effects through evaluative conditioning were found by Houben, Havermans, and Wiers (2010), but this time using implicit measures of associations. It was found that EC can lead to more negative implicit measures of associations with alcohol and reduced drinking behaviour. Houben, Havermans, et al. (2010) therefore proposed that EC can be a useful intervention method for reducing alcohol abuse. The current study examined whether implicit measures of attitudes towards snack food can be changed by evaluative conditioning, and whether this conditioning procedure affects food consumer behaviour.

A popular paradigm to obtain implicit measures of these affective evaluations is the implicit association test (IAT; Greenwald, McGhee, 
\& Schwartz, 1998). This procedure is based on the speed and accuracy of responding to visually presented stimuli. The IAT assesses associations between a target dimension (e.g., high-fat foods vs. low-fat foods) and an attribute dimension (e.g., positive vs. negative). The idea is that when a person holds a strong association between a target category (e.g., high-fat foods) and a certain attribute category (e.g., positive), responses will be faster and more accurate than when associations are weak. However, a potential problem with this particular food-IAT might be that some participants are reminded of their dietary goals, because both high and low-fat food stimuli are presented. Particularly the contrast between these two food categories may point out that high-fat foods are more unhealthy and low-fat foods more healthy (see Houben, Roefs, \& Jansen, 2010). A related problem is that the IAT assesses relative associations. This implies that the food IAT can only reveal whether associations with high-fat foods are either more positive (than negative) or more negative (than positive) in comparison to low-fat foods.

Houben, Roefs, et al. (2010) tried to overcome these two problems by using two unipolar variants of the single category IAT (sc-IAT; Karpinski \& Steinman, 2006). The sc-IAT is a non-relative measure in that it only uses a single target category (e.g., high-fat food) and that positive and negative associations are assessed separately (contrasted with a neutral category). Advantages include that an absolute measure of associations with high-fat foods can be obtained, that both positive and negative associations can be assessed, and that participants are likely not reminded of their dieting goal because the obviously healthier low-fat foods are not presented (Houben, Roefs, et al., 2010). To assess whether EC influences implicit measures of associations with high-fat foods, two unipolar variants of the Sc-IAT were used in the present study: one that assesses positive associations, and one that assesses negative associations.

As EC has proven to influence drinking behaviour (Houben, Havermans, et al., 2010), it may also affect people's food consumer behaviour. Recently, Nederkoorn, Guerrieri, Havermans, Roefs, and Jansen (2009) developed a web-based supermarket task to measure food consumer behaviour. In this task, participants receive an imaginary budget to spend in a virtual supermarket. In doing so, food consumer behaviour (i.e., snack calories, non-snack calories, and total calories bought) is assessed. A second aim of the current study is to test whether the EC procedure is effective in altering food consumer behaviour as reflected in the virtual supermarket task.

In sum, the present study examined whether evaluative conditioning can alter implicit measures of food associations and food consumer behaviour. For participants in the experimental condition, the EC procedure paired high-fat snack-food items with negative USs and low-fat fruit items with positive USs. In the control condition, high-fat and low-fat food items were randomly associated with both positive and negative USs. Positively and negatively valenced body shapes were used as positive and negative USs respectively. A positive and negative unipolar high-fat sc-IAT and the virtual supermarket task (VST; Nederkoorn et al., 2009) were used to assess associations with high-fat foods and food consumer behaviour. It was hypothesised that, compared to participants in the control condition, those in the experimental condition would show increased negative and reduced positive implicit measures of associations with snack foods on the sc-IATs. Moreover, it was expected that participants in the experimental condition would buy fewer total calories, fewer snack calories and more fruit calories in the VST than participants in the control condition.

\section{Method}

\subsection{Pilot study}

In a pilot study, the valence of pictures of female body shapes was assessed. This was done to select the body shapes that are most positive and most negative to women. The most positively and most negatively rated body shapes were then used as USs in the main study's EC procedure.

\subsubsection{Participants}

Twenty female participants took part in the pilot study (age: $M=35.05, S D=17.08$; BMI: $M=22.92, S D=2.94$ ).

\subsubsection{Materials and measures}

Forty-eight images of females were selected from the internet. In selecting the images it was made sure that the woman's body was clearly visible and that a wide range of different bodies were presented. Also, variables like age, ethnicity, and hair and skin colour were varied. All images were edited using Adobe Photoshop CS3. The women were placed on a 25\% grey background (192R, 192G, 192B), and all images were presented on a computer monitor in a unique random order for each participant. The participant indicated on visual analogue scales (VAS, $150 \mathrm{~mm}$ ): (1) the attractiveness of the woman's body and (2) how much they would like to have that body. Afterwards, age, height, and weight of the participant were asked.

For the data-analysis, VAS scores were transformed to a scale from 0 to 100 in which higher scores reflect more positive evaluations of the image. Because the two items were highly correlated $(r=.89$, $p<.01$ ), scores on both VAS measures were averaged per image, yielding 48 mean scores (range 8.2-75.4). The images with the top six $(M=72.2, S D=20.3)$ and bottom six $(M=12.3, S D=11.5)$ mean scores were used in the main study. Overall, lean bodies were judged as more positive than were overweight bodies.

\subsection{Main study}

\subsubsection{Participants}

An advertisement posted in local supermarkets and on popular women's lifestyle websites invited female participants to participate in a study on eating behaviour. All participants were tested via the Internet (for a discussion of the validity of internet testing see Houben \& Wiers, 2008). The study was approved by the ethical committee of the Faculty of Psychology and Neuroscience of Maastricht University, the Netherlands. Eighty-five female participants completed the study. Participants were randomly assigned to one of the two conditions. Age (experimental: $M=34.14, S D=12.87$; control: $M=34.23$, $S D=13.49$ ) and BMI (experimental: $M=24.14, S D=6.64$; control: $M=24.48, S D=3.92$ ) did not differ between the experimental and control group (age: $t(83)=0.18 p=.86$; BMI: $t(82)=1.21, p=.23$ ). ${ }^{1}$ As a compensation for participation, six iPods were raffled amongst the participants.

\subsubsection{Materials}

1.2.2.1. Evaluative conditioning. In a picture-picture evaluative conditioning task, a snack or fruit picture (the CS) was presented in one of four quadrants of the computer screen. Participants had to categorise the images by pressing one of two keys on the keyboard. To limit awareness of the study's purpose, the participant did not categorise them by fat content, but by spatial location. She was instructed to press the 'e-key' when the CS appeared in one of the two top quadrants and the 'i-key' when it appeared in one of the bottom quadrants. Next, a picture of a female's body shape (the US) briefly (400 ms) appeared in the same quadrant. This procedure was repeated for 144 trials with an inter-trial interval of $1500 \mathrm{~ms}$. Of the 144 trials, 72 trials displayed snack CSs and 72 trials displayed fruit CSs. As there were twelve CSs (six snacks: chips, chocolate, cookies, French fries, hamburger, and pizza; and six fruits: apple, grapes, kiwi,

\footnotetext{
${ }^{1}$ Height and weight data of one participant were missing.
} 
melon, raspberries, and strawberries) and twelve USs (six positively and six negatively valenced bodies), all stimuli were presented twelve times in the EC procedure. In the experimental condition, snack images were always paired with negatively valenced body shapes, whereas fruit images were always paired with positively valenced body shapes. For participants in the control condition the CS-US pairings were random so that both the snack and fruit stimuli were followed by pictures of positively valenced body shapes (50\%) and negatively valenced body shapes (50\%).

1.2.2.2. Positive and negative unipolar sc-IAT. Both sc-IATs consisted of three blocks. In the first block, categorization of attribute concepts (pleasant vs. neutral or unpleasant vs. neutral) was practised. The labels of the attribute categories were displayed in the left and right top corners of the screen. Attribute stimuli appeared in the centre and had to be categorised to one of the attribute categories by pressing either the 'e-key' (category in left top corner of the screen) or 'i-key' (category in right top corner of the screen).

We used similar attribute stimuli to those Houben, Roefs, et al. (2010) used in their study. In the positive sc-IAT, a positive attribute category (label: 'pleasant'; six attribute stimuli: tasty, delicious, nice, delightful, heavenly, outstanding) was contrasted with a neutral attribute category (label 'neutral'; six attribute stimuli: average, undefined, general, normal, usual, everyday), whereas in the negative sc-IAT, a negative attribute category (label 'unpleasant'; six attribute stimuli: tasteless, unsavoury, bad, nasty, awful, disgusting) was contrasted with the identical neutral attribute category.

In the second block the target category of 'snacks' was added. The same six snack images that were used as CSs in the EC task were used as target stimuli. The target category (label: 'snack') and the valenced attribute category were assigned to one response key, and the neutral attribute category to the other (e.g., 'e-key': snack + pleasant; 'i-key': neutral). The third block only differed from the second block in the reversal of the key-assignment for the target category. In this block the target category was now paired with the neutral, rather than the valenced attribute category (e.g., ‘e-key’: pleasant; 'i-key': snack + neutral).

Block 1 consisted of 24 practice trials. In blocks 2 and 3, 42 responses (30 target and 12 attribute stimuli) were assigned to one response key and 30 attribute responses to the other key, for a total of 72 trials. This 5:2:5 ratio was applied to keep the number of left and right responses fairly equal. Both the order of the second and the third block and the order in which the two sc-IATs were presented were balanced over participants.

1.2.2.3. Virtual supermarket task. In the virtual supermarket task (VST), the participant was given an imaginary budget of $€ 15$. With this budget she was asked to buy as much food and drinks she would need if she did not leave her house for one day. The virtual shop was organised in main categories (e.g., vegetables, fruits, etc.), subcategories (e.g., fresh vegetables, canned vegetables, and frozen vegetables), and products (640 in total). After the participant confirmed that she had selected all she needed for the day, calories from snacks, calories from fruits, and total calories were calculated as the dependent variables.

1.2.2.4. Procedure. After giving her consent, the participant first completed the evaluative conditioning task (15 min). Second, a positive high-fat and a negative high-fat unipolar sc-IAT were performed in a balanced order (10 min each), after which the VST (10 min) was done. To check whether the participant was aware of CS-US contingencies in the EC procedure, an open-ended question at the end of the study asked if she perceived anything typical about the way in which the pictures were presented. Finally, age, height, and weight of the participant were asked.

\section{Results}

The data of three additional participants (experimental group), whose snack calorie purchase was more than three standard deviations above the mean, were discarded. The final sample consisted of 85 participants: 41 in the experimental condition and 44 in the control condition. To test whether the results differed between the two conditions, independent samples t-tests were used for both sc-IAT variants and the VST. Sc-IAT latencies under $300 \mathrm{~ms}$ (positive sc-IAT: 0,1\%; negative sc-IAT: $0,1 \%$ ) and over $3000 \mathrm{~ms}$ (positive sc-IAT: 1,6\%; negative sc-IAT: $1.5 \%$ ) were excluded from analyses (cf. Greenwald, Nosek, \& Banaji, 2003). Sc-IAT effects were calculated by subtracting participant's mean response latency on the valenced block from their mean response latency on the neutral block. So, higher scores on the sc-IATs imply more valenced associations with snack foods. Sc-IAT results are given in milliseconds.

\subsection{Positive unipolar Sc-IAT}

On the positive sc-IAT, higher scores indicate faster performance for the 'snack + positive' block than for the 'snack + neutral' block, which means that higher scores imply more positive associations with snack foods. Results of the positive unipolar sc-IAT variant confirmed our predictions. Analyses revealed a significant difference between the two conditions, $t(83)=2.08, p=.04, d=0.46$. The sc-IAT effect was less positive in the experimental condition $(M=-1.07$, $S D=111.2)$ than in the control condition $(M=47.4, S D=100.3)$. This difference indicates that participants in the experimental condition showed less positive associations with snack foods than those in the control condition.

\subsection{Negative unipolar Sc-IAT}

For the negative sc-IAT variant, higher scores indicate faster performance for the 'snack + negative' block than for the 'snack + neutral' block, which means that higher scores imply more negative associations with snack foods. Our hypothesis for this sc-IAT variant was also confirmed as the two conditions differed significantly, $t(83)=$ 2.04, $p=.04, d=0.59$. Participants in the experimental condition showed more negative associations with snack foods $(M=56.0$, $S D=95.6)$ than did participants in the control condition $(M=-7.87$, $S D=119.7)$.

\subsection{Virtual supermarket task}

Analyses of the snack calories, fruit calories, and total calories yielded no significant differences between the two conditions (see Table 1). Participants in the experimental and control conditions bought similar numbers of calories from snack food, $t(83)=1.06$, $p=.29$, and from fruits, $t(83)=0.02, p=.98$. Also, the total number of calories that was bought was similar in both conditions, $t(83)=0.88$, $p=.38$. See Table 1 for relevant means and SDs.

Table 1

Means and standard deviations $(S D)$ for the virtual supermarket task, per condition and type of calories.

\begin{tabular}{|c|c|c|}
\hline & Experimental condition & Control condition \\
\hline & $M(S D)$ & $M(S D)$ \\
\hline Calories from snacks & 397 (717) & $246(595)$ \\
\hline Calories from fruit & $224(332)$ & $222(241)$ \\
\hline Total calories & $4852(2577)$ & $5333(2465)$ \\
\hline
\end{tabular}




\subsection{Contingency awareness}

As indicated by the open-ended question, 15 participants in the experimental condition had become aware of specific CS-US contingencies. Further analysis showed no differences between contingency aware and contingency unaware participants on the main dependent variables: positive sc-IAT, $t(39)=.02, p=.99$, negative sc-IAT, $t(39)=$ $1.49, p=.15$, calories from snack food, $t(39)=.87, p=.39$, calories from fruits, $t(39)=.65, p=.52$, and total calories, $t(39)=.80, p=.43$.

\section{Discussion}

The present study examined the effect of a picture-picture evaluative conditioning procedure on implicit measures of associations with snack foods and on food consumer behaviour. In the experimental condition snack foods were paired with negatively valenced female body shapes, and fruits were paired with positively valenced body shapes. In the control condition snack and fruit stimuli were randomly paired with positively and negatively valenced body shapes. Generally, our pilot showed that lean bodies were rated positively and overweight bodies were rated negatively. This may have benefitted the EC procedure due to the stereotypical perspective that overweight people typically consume snack food, whilst lean people eat more fruits. After the EC procedure, participants in the experimental condition showed both reduced positive and increased negative associations with snack foods, as compared to participants in the control condition. Hence, pairing high-caloric snacks with negatively valenced body shapes and fruits with positively valenced body shapes can change women's implicit measures of associations with snack foods.

This finding adds to similar earlier research by indicating that, in addition to explicit measures of affective evaluations (e.g., Dwyer, Jarratt, \& Dick, 2007; Lascelles et al., 2003), implicit measures of affective evaluations with foods can also be altered by repeatedly showing food images paired with certain body shapes. These results also fit with findings by Hermans, Baeyens, Lamote, Spruyt, and Eelen (2005). Their study also showed implicit evaluative learning effects, though in their EC procedure food cues were paired with positive or negative odours rather than with pictures of body shapes.

Contingency awareness in the EC procedure of the current study (i.e., the knowledge that particular CS's and US's are paired) was assessed through an open-ended question. Despite the limitations of such a broad measurement (see Field, 2000), our results did not depend on contingency awareness, as no differences on the main dependent measures were observed between aware and unaware participants. In the past, EC has proven to be effective with (e.g., Pleyers, Corneille, Luminet, \& Yzerbyt, 2007), but also without (e.g., Baeyens, Eelen, \& van den Bergh, 1990) participants' awareness of CS-US contingencies. A meta-analysis by Hofmann, De Houwer, Perugini, Baeyens, and Crombez (2010) found that EC effect sizes were almost three times higher for contingency aware participants compared to participants who were unaware of the CS-US pairings. Nevertheless, contingency awareness does not seem to be a necessary condition as EC effects of contingency unaware participants differed significantly from zero in this meta-analysis. Furthermore, Pleyers et al. (2007) contend that contingency awareness is not as black-andwhite as most researchers suggest. Participants rarely become aware of all CS-US contingencies. Typically only some contingencies are identified whilst others are not. Additionally, one should distinguish between contingency awareness and demand awareness (Field, 2000). Demand aware participants know of the experimental hypotheses. Moreover, to affect our results participants would not only have to be demand aware, they would also need to have knowledge on how to influence the IAT, which is unlikely without prior knowledge, experience, or information (e.g., Steffens, 2004).
Although affective associations to snack foods were altered by the EC procedure, no behavioural effects were found. Participants in both groups bought equal amounts of food in the virtual supermarket task. These results do not fit with earlier findings showing that implicit measures of associations are predictive of consumer choice. Perugini (2005) and Richetin et al. (2007), for instance, found that participants' IAT scores could predict the choice between a candy bar and a piece of fruit. A possible explanation for failing to obtain this behavioural effect can be found in the dual-process models of information processing (Fazio, 1990; Strack \& Deutsch, 2004). According to these models, reflective and deliberate cognitive processes encourage people to buy and eat healthy foods, whereas automatic cognitive processes compel people to follow their impulses and consume palatable, high-fat foods. The discordance between scores on the scIAT and VST could therefore suggest that different cognitive processes drive the two tasks. Whereas, the sc-IAT outcome reflects automatic processes, deciding what foods to buy may be more of a reflective process as it encompasses the consideration of numerous factors (e.g., the food's palatability, caloric content, price, and how time consuming it is to prepare the product). Herein, doing groceries is quite distinct from simply choosing between a candy-bar and an apple. The EC procedure may thus have been more successful in altering automatic than more deliberative processes, and therefore affected only the IAT measures.

Our findings are of relevance for restrained eating. Few restrained eaters are able to maintain their diet consistently (Herman \& Polivy, 1980 ) and are prone to indulge after being exposed to high-caloric, palatable foods (e.g., Fedoroff, Polivy, \& Herman, 2003; Jansen \& Van den Hout, 1991). As the shifts in implicit measures of food associations were found in a non-selected sample, it suggests that this form of conditioning could reduce positive associations with high-fat food in all females. Interestingly, however, equivocal empirical support exists for the notion that restrained eaters already hold more positive associations with high-caloric foods than do unrestrained eaters (for a review, see Roefs et al., 2011). Whereas some studies found more positive implicit measures of associations for high-caloric palatable food in restrained eaters (e.g., Hoefling \& Strack, 2008; Houben, Roefs, et al., 2010), others found the opposite effect (e.g., Vartanian, Polivy, \& Herman, 2004) or no difference between restrained and unrestrained eaters (e.g., Roefs, Herman, MacLeod, Smulders, \& Jansen, 2005).

Although no effects on food choice when grocery shopping emerged in our study, the reduced positive associations with highcaloric foods after EC could still be of help in maintaining one's diet. Future studies could for instance assess EC's effect on more impulsive food choices like grabbing a snack on your way home from work, or having lunch in the school cafeteria. Also, the virtual supermarket task could be modified to make participants' food choices more in line with their impulses. Impulsive decision making could be selectively enhanced by depleting the self's regulatory resources (Strack \& Deutsch, 2004). Adding boundary conditions like time restraint and/or cognitive load to the virtual supermarket task may therefore generate the desired effects and make participants in the experimental condition buy healthier products. To improve people's dietary intake, future research should thus further investigate the impact of the shift in implicit measures of food evaluations on food consumer behaviour.

Two methodological limitations may have had an effect on the results of the present study. As noted earlier, the sc-IAT was used because with this procedure it is possible to assess associations with only one category, in the current study, high-fat foods. By not presenting the contrast between high-fat and low-fat food stimuli in the sc-IAT, dietary goals were expected not to be activated in participants during ScIAT performance (Houben, Roefs, et al., 2010). Had we used a traditional IAT, contrasting high-fat and low-fat foods, then it may have been more difficult to show a difference between the two EC conditions, as participants in the control condition may have been more negative 
about high-fat foods because of an activation of dietary goals during their IAT performance. However, our EC task did include the contrast category low-fat food (i.e., fruits) in both the experimental and the control conditions, possibly leading to the activation of dietary goals in this task. The inclusion of a contrast category was necessary in our EC task as it would have been difficult to have a good control condition if only high-fat foods and negatively valenced bodies had been included in the experimental condition. This would leave no possibility for a random pairing of CS and US as a control condition. Though we did find differences on our implicit measures, it may have been the cause of not finding differences on the behavioural measure. Even though there was some time delay between the EC task and our behavioural measure (i.e., the virtual supermarket task), the possible activation of dietary goals in the EC task may have influenced participants' food consumer behaviour. A second limitation is that our findings cannot be fully generalised to the category of snack foods, as we used the same 6 stimuli in the EC task as in the Sc-IAT. So, we do not know if the EC-effects would generalise if other stimuli representing the category of snack-foods had been used in the sc-IAT.

In sum, the evaluative conditioning procedure was found to successfully alter associations with high-fat foods in females. Although consumer behaviour as assessed in a virtual supermarket task was not affected, future research needs to include other measures of food consumption behaviour, preferably addressing more impulsive buying behaviour.

\section{Role of Funding Sources}

No external funding sources were available for this study. Funding was fully provided by Maastricht University.

\section{Contributors}

All authors were involved in the study design and writing of the protocol. Herbert Lebens collected all data. Katrijn Houben, Chantal Nederkoorn and Anne Roefs were responsible for programming the experimental tasks. Herbert Lebens and Anne Roefs conducted the statistical analyses. Herbert Lebens wrote the first draft of the manuscript and all authors contributed to and have approved the final manuscript.

\section{Conflict of Interest}

There are no conflicts of interest.

\section{References}

Baeyens, F., Eelen, P., \& Crombez, G. (1995). Pavlovian associations are forever: On classical conditioning and extinction. Journal of Psychophysiology, 9, 127-141.

Baeyens, F., Eelen, P., \& van den Bergh, O. (1990). Contingency awareness in evaluative conditioning: A case for unaware affective-evaluative learning. Cognition and Emotion, 4, 3-18, doi:10.1080/02699939008406760.

De Houwer, J., Baeyens, F., \& Eelen, P. (1994). Verbal evaluative conditioning with undetected US presentations. Behaviour Research and Therapy, 32, 629-633, doi:10.1016/0005-7967(94)90017-5.

De Houwer, J., Teige-Mocigemba, S., Spruyt, A., \& Moors, A. (2009). Implicit measures: A normative analysis and review. Psychological Bulletin, 135, 347-368, doi:10.1037/ a0014211.

Dwyer, D. M., Jarratt, F., \& Dick, K. (2007). Evaluative conditioning with foods as CSs and body shapes as USs: No evidence for sex differences, extinction, or overshadowing. Cognition E Emotion, 21, 281-299, doi:10.1080/02699930600551592.

Fazio, R. H. (1990). Multiple processes by which attitudes guide behaviour: The MODE model as an integrative framework. In M. P. Zanna (Ed.), Advances in experimental social psychology (pp. 75-109). San Diego, CA: Academic Press.

Fedoroff, I. C., Polivy, J., \& Herman, C. P. (2003). The specificity of restrained versus unrestrained eaters' responses to food cues: general desire to eat, or craving for the cued food? Appetite, 41, 7-13, doi:10.1016/S0195-6663(03)00026-6.

Field, A. P. (2000). I like it, but I'm not sure why: Can evaluative conditioning occur without conscious awareness? Consciousness and Cognition, 9, 13-36, doi:10.1006/ ccog.1999.0402.
Greenwald, A. G., McGhee, D. E., \& Schwartz, J. L. K. (1998). Measuring individual differences in implicit cognition: The implicit association test. Journal of Personality and Social Psychology, 74, 1464-1480, doi:10.1037/0022-3514.74.6.1464.

Greenwald, A. G., Nosek, B. A., \& Banaji, M. R. (2003). Understanding and using the implicit association test: I. An improved scoring algorithm. Journal of Personality and Social Psychology, 85, 197-216, doi:10.1037/0022-3514.85.2.197.

Herman, C. P., \& Polivy, J. (1980). Restrained eating. In A. J. Stunkard (Ed.), Obesity (pp. 208-225). Philadelphia: Saunders.

Hermans, D., Baeyens, F., Lamote, S., Spruyt, A., \& Eelen, P. (2005). Affective priming as an indirect measure of food preferences acquired through odor conditioning. Experimental Psychology, 52, 180-186, doi:10.1027/1618-3169.52.3.180.

Hoefling, A., \& Strack, F. (2008). The tempting effect of forbidden foods: High calorie content evokes conflicting implicit and explicit evaluations in restrained eaters. Appetite, 51, 681-689, doi:10.1016/j.appet.2008.06.004.

Hofmann, W., De Houwer, J., Perugini, M., Baeyens, F., \& Crombez, G. (2010). Evaluative conditioning in humans: A meta-analysis. Psychological Bulletin, 136(3), 390-421, doi:10.1037/a0018916

Houben, K., Havermans, R. C., \& Wiers, R. W. (2010). Learning to dislike alcohol: Conditioning negative implicit attitudes towards alcohol and its effect on drinking behaviour. Psychopharmacology, 211, 79-86, doi:10.1007/s00213-010-1872-1.

Houben, K., Roefs, A., \& Jansen, A. (2010). Guilty pleasures: Implicit preferences for low and high calorie food in restrained eating. Appetite, 55, 18-24, doi:10.1016/j.appet. 2010.03.003.

Houben, K., \& Wiers, R. W. (2008). Measuring implicit alcohol associations via the internet: Validation of Web-based Implicit Association Tests. Behaviour Research Methods, 40, 1134-1143, doi:10.3758/BRM.40.4.1134.

Jansen, A., \& Van den Hout, M. A. (1991). On being led into temptation: "Counterregulation" of dieters after smelling a "preload”. Addictive Behaviours, 16, 247-253, doi:10.1016/0306-4603(91)90017-C.

Karpinski, A., \& Steinman, R. B. (2006). The single-category implicit association test as a measure of implicit social cognition. Journal of Personality and Social Psychology, 91, 16-32, doi:10.1037/0022-3514.91.1.16.

Lascelles, K. R., Field, A. P., \& Davey, G. C. (2003). Using foods as CSs and body shapes as UCSs: A putative role for associative learning in the development of eating disorders. Behavioural Therapy, 34, 213-235, doi:10.1016/S0005-7894(03)80014-X.

Maison, D., Greenwald, A. G., \& Bruin, R. H. (2004). Predictive validity of the implicit association test in studies of brands, consumer attitudes, and behaviour. Journal of Consumer Psychology, 14(4), 405-415, doi:10.1207/s15327663jcp1404_9.

Martin, I., \& Levey, A. B. (1978). Evaluative conditioning. Advances in Behaviour Research and Therapy, 1, 57-102, doi:10.1016/0146-6402(78)90013-9.

Nederkoorn, C., Guerrieri, R., Havermans, R. C., Roefs, A., \& Jansen, A. (2009). The interactive effect of hunger and impulsivity on food intake and purchase in a virtual supermarket. International Journal of Obesity, 33, 905-912, doi:10.1038/ijo.2009.98.

Perugini, M. (2005). Predictive models of implicit and explicit attitudes. British Journal of Social Psychology, 44, 29-45, doi:10.1348/014466604X23491.

Pleyers, G., Corneille, O., Luminet, O., \& Yzerbyt, V. (2007). Aware and (dis)liking: Itembased analyses reveal that valence acquisition via evaluative conditioning emerges only when there is contingency awareness. Journal of Experimental Psychology. Learning, Memory, and Cognition, 33(1), 130-144, doi:10.1037/0278-7393.33.1.130.

Poulton, R. \& Menzies, R. G. (2002). Fears born and bred: Toward a more inclusive theory of fear acquisition. Behaviour Research and Therapy, 40, 197-208, doi:10.1016/ S0005-7967(01)00052-3.

Richetin, J., Perugini, M., Prestwich, A., \& O'Gorman, R. (2007). The IAT as a predictor of food choice: The case of fruits versus snacks. International Journal of Psychology, 42(3), 166-173, doi:10.1080/00207590601067078.

Roefs, A., Herman, C. P., MacLeod, C. M., Smulders, F. T. Y., \& Jansen, A. (2005). At first sight: How do restrained eaters evaluate high-fat foods? Appetite, 44, 103-114, doi:10.1016/j.appet.2004.08.001

Roefs, A., Huijding, J., Smulders, F. T. Y., MacLeod, C. M., de Jong, P. J., Wiers, R. W., et al. (2011). Implicit measures of association in psychopathology research. Psychological Bulletin, 137, 149-193.

Rozin, P., \& Millman, L. (1987). Family environment, not heredity, accounts for family resemblances in food preferences and attitudes: A twin study. Appetite, 8, 125-134, doi:10.1016/S0195-6663(87)80005-3.

Rozin, P., Wrzesniewski, A., \& Byrnes, D. (1998). The elusiveness of evaluative conditioning. Learning and Motivation, 29, 397-415, doi:10.1006/lmot.1998.1012.

Steffens, M. C. (2004). Is the implicit association test immune to faking? Experimental Psychology, 51, 165-179, doi:10.1027/1618-3169.51.3.165.

Strack, F., \& Deutsch, R. (2004). Reflective and impulsive determinants of social behaviour. Personality and Social Psychology Review, 8, 220-247, doi:10.1207/ s15327957pspr0803_1.

Vartanian, L. R., Polivy, J., \& Herman, C. P. (2004). Implicit cognitions and eating disorders: Their application in research and treatment. Cognitive and Behavioural Practice, 11(2), 160-167, doi:10.1016/S1077-7229(04)80027-0.

Wang, Y., \& Beydoun, M. A. (2007). The obesity epidemic in the United States - gender, age, socieconomic, racial/ethnic, and geographic characteristics: A systematic review and meta-analysis. Epidemiologic Reviews, 29, 6-23, doi:10.1093/epirev/mxm007. 